\title{
Boron-10 Lined Proportional Counter Wall Effects
}

Edward R. Siciliano

Richard T. Kouzes

May 2012

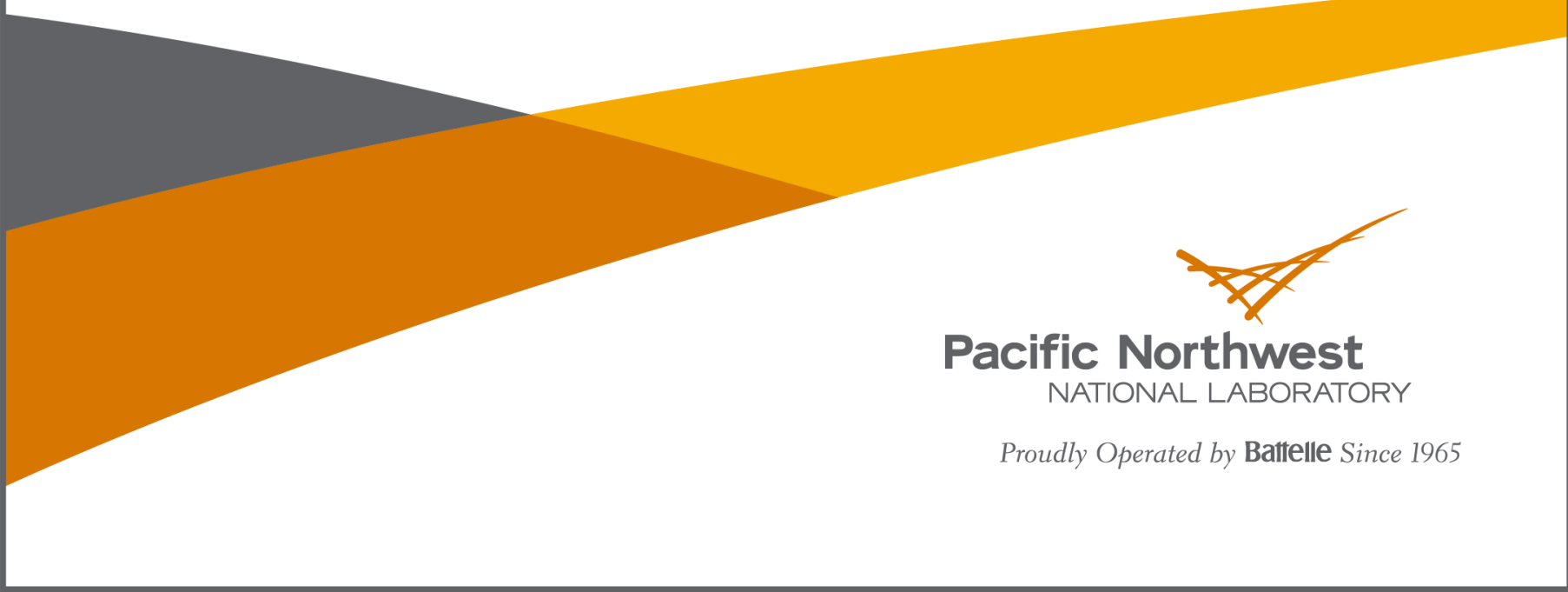




\title{
DISCLAIMER
}

This report was prepared as an account of work sponsored by an agency of the United States Government. Neither the United States Government nor any agency thereof, nor Battelle Memorial Institute, nor any of their employees, makes any warranty, express or implied, or assumes any legal liability or responsibility for the accuracy, completeness, or usefulness of any information, apparatus, product, or process disclosed, or represents that its use would not infringe privately owned rights. Reference herein to any specific commercial product, process, or service by trade name, trademark, manufacturer, or otherwise does not necessarily constitute or imply its endorsement, recommendation, or favoring by the United States Government or any agency thereof, or Battelle Memorial Institute. The views and opinions of authors expressed herein do not necessarily state or reflect those of the United States Government or any agency thereof.

\author{
PACIFIC NORTHWEST NATIONAL LABORATORY \\ operated by \\ BATTELLE \\ for the \\ UNITED STATES DEPARTMENT OF ENERGY \\ under Contract DE-AC05-76RL01830
}

Printed in the United States of America
Available to DOE and DOE contractors from the
Office of Scientific and Technical Information,
P.O. Box 62, Oak Ridge, TN 37831-0062;
ph: (865) 576-8401
fax: (865) 576-5728
email: reports@adonis.osti.gov

Available to the public from the National Technical Information Service, U.S. Department of Commerce, 5285 Port Royal Rd., Springfield, VA 22161

ph: (800) 553-6847

fax: (703) 605-6900

email: orders@ntis.fedworld.gov

online ordering: http://www.ntis.gov/ordering.htm 
PNNL-21368

\section{Boron-10 Lined Proportional Counter Wall Effects}

Edward R. Siciliano

Richard T. Kouzes

May 2012

Pacific Northwest National Laboratory

Richland, Washington 99352 


\section{Executive Summary}

The Department of Energy Office of Nuclear Safeguards (NA-241) is supporting the project "Coincidence Counting With Boron-Based Alternative Neutron Detection Technology" at Pacific Northwest National Laboratory (PNNL) for development of an alternative neutron coincidence counter. The goal of this project is to design, build and demonstrate a boron-lined proportional tube based system in the configuration of a coincidence counter.

This report provides information about how variations in proportional counter radius and gas pressure in a typical coincident counter design might affect the observed signal from boron-lined tubes. The "wall effect" is when one of the reaction products from neutron absorption on ${ }^{10} \mathrm{~B}$ enters the proportional gas, but loses only some of its energy in the gas before hitting the opposite wall. The modeling shows that the wall effect distorts the observed signal, and counts would be lost from the signal below the low energy cutoff for the smaller diameter tubes if the gas pressure were also low. A discussion comparing tubes to parallel plate counters is also included. 


\section{Acronyms and Abbreviations}

$\begin{array}{ll}\text { ANCC } & \text { alternate neutron coincidence counter } \\ \text { atm } & \text { atmosphere } \\ \text { FWHM } & \text { full width at half maximum } \\ \text { GEB } & \text { Gaussian energy broadening } \\ \text { KE } & \text { kinetic energy } \\ \text { MCNP } & \text { Monte Carlo N-Particle } \\ \text { NCC } & \text { neutron coincidence counter } \\ \text { PH } & \text { pulse height } \\ \text { PNNL } & \text { Pacific Northwest National Laboratory }\end{array}$




\section{Contents}

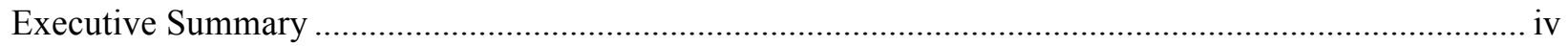

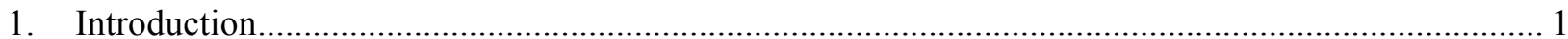

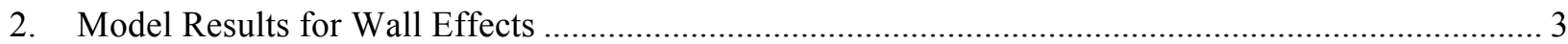

3. Parallel Plate Compared to Cylindrical Counters ........................................................................... 14

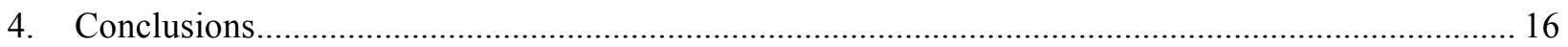

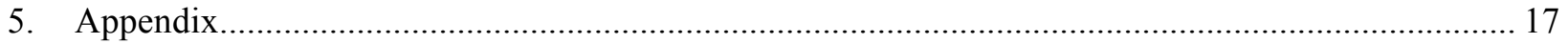

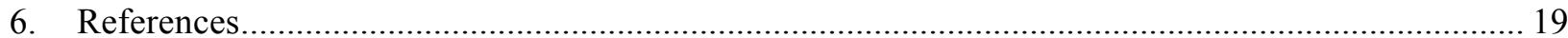




\section{Figures}

\section{Figures}

Figure 1.1. Pulse height spectrum from assembly of $2.54 \mathrm{~cm}$ diameter boron-lined counters................... 2

Figure 2.1. Currents and pulse heights from $2.54 \mathrm{~cm}$ tubes showing GEB and wall effects..................... 5

Figure 2.2. Energy deposited from array of $5.08 \mathrm{~cm}$ diameter boron-lined tubes. ..................................... 6

Figure 2.3. Energy deposited from array of $2.54 \mathrm{~cm}$ diameter boron-lined tubes. ................................... 6

Figure 2.4. Energy deposited from array of $1.27-\mathrm{cm}$ diameter boron-lined tubelets.................................. 7

Figure 2.5. Energy deposited from array of 8 - $\mathrm{mm}$ diameter boron-lined tubelets. .................................. 8

Figure 2.6. Energy deposited from array of 4-mm diameter boron-lined tubelets. .................................. 8

Figure 2.7. Total Pulse-Height Comparisons for 1.0-atm gas pressure ...................................................... 9

Figure 2.8. Total Pulse-Height Comparisons for $0.3-\mathrm{atm}$ gas pressure .................................................. 9

Figure 2.9. Loss of counts as function of LEC for 14, 5.08-cm diameter tubes. .................................... 10

Figure 2.10. Loss of counts as function of LEC for 18, 2.54-cm diameter tubes................................... 11

Figure 2.11. Loss of counts as function of LEC for $14 \times 7,1.27-\mathrm{cm}$ diameter tubelets........................... 11

Figure 2.12. Loss of counts as function of LEC for $14 \times 19,8-\mathrm{mm}$ diameter tubelets.............................. 12

Figure 2.13. Loss of counts as function of LEC for $14 \times 50,4-\mathrm{mm}$ diameter tubelets............................... 13

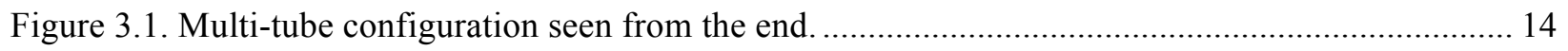

Figure 3.2. Parallel plate configuration seen from the end. .............................................................. 14

Figure 3.3. Parallel plate configuration seen from the end. …........................................................... 15

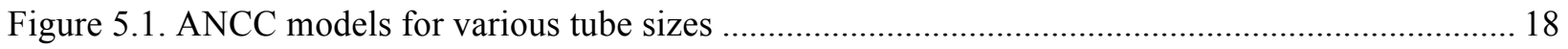




\section{Introduction}

The Department of Energy Office of Nuclear Safeguards (NA-241) is supporting the project Coincidence Counting With Boron-Based Alternative Neutron Detection Technology at Pacific Northwest National Laboratory (PNNL) for development of an alternative neutron coincidence counter [Kouzes 2012].

For the development of coincidence counters based on alternative technologies, both parallelplate multi-wire proportional counters and single-wire cylindrical proportional counters are being evaluated, each using a ${ }^{10} \mathrm{~B}$ lining as the active material. The typical thickness of the lining is of the order of 2 microns. When thermal neutrons are captured by ${ }^{10} \mathrm{~B}$ in the lining of the tube, the center-of-mass motion can be ignored, and the two resulting reaction products $\left({ }^{4} \mathrm{He}\right.$ and ${ }^{7} \mathrm{Li}$ nuclei) can be assumed to travel in opposite directions and share the reaction Q-value energy in proportion to their relative masses. For the predominant branch $(\sim 94 \%)$ of that capture reaction, the ${ }^{7} \mathrm{Li}$ nucleus is left in its excited state with $\mathrm{Q}=2.310 \mathrm{MeV}$, giving $0.840 \mathrm{MeV}$ and $1.470 \mathrm{MeV}$ for the initial kinetic energies (KEs) of the ${ }^{7} \mathrm{Li}$ and ${ }^{4} \mathrm{He}$, respectively. For the less probable ${ }^{7} \mathrm{Li}$ ground state branch, $\mathrm{Q}=2.792 \mathrm{MeV}$, giving higher initial energies of $1.015 \mathrm{MeV}$ and $1.777 \mathrm{MeV}$, respectively.

Because the initial direction of the two reaction products are constrained to be in opposite directions, at best only one per capture event is directed towards the center of the tube. In ratio to the total number of captures, the effect of further collisions within the lining results with about half of the reaction products eventually escaping from a thin boron lining and enter the proportional gas in the counter (typically an argon-methane or argon- $\mathrm{CO}_{2}$ mixture at one atmosphere or less). Once one of these particles enters the gas, having lost some of its energy in the lining, it may deposit all or some of its remaining energy in the gas before striking an opposing wall. The upper limit of that energy deposition is bounded by the initial KEs of the reaction products.

The pulse-height spectrum shown in Figure 1.1 illustrates how the above kinematic constraints are manifested in an actual system. This spectrum was measured at PNNL from a commercially available system of 20 boron-lined tubes of $2.54 \mathrm{~cm}$ diameter [Lintereur 2010]. It is seen to have a double-plateau shape, which can be interpreted as resulting from different regions of $\mathrm{KE}$ available to the reaction products. Because the ${ }^{4} \mathrm{He}$ has a higher maximum $\mathrm{KE}$, it can contribute throughout the spectrum, but the ${ }^{7} \mathrm{Li}$, with the smaller maximum $\mathrm{KE}$, may contribute only to the lower region of the spectrum. The sum of these two, therefore, is what causes the characteristic double-plateau shape.

One feature observed in the pulse height spectrum of Figure 1.1 that is of particular interest is the rate of signal drop-off at the edges of the ${ }^{7} \mathrm{Li}$ and ${ }^{4} \mathrm{He}$ plateaus. Note that the drop-off rate near channel 110 (the edge of the ${ }^{7} \mathrm{Li}$ contribution) is steeper than that at the ${ }^{4} \mathrm{He}$ end of the spectrum. This difference may be a result of the wall effect upon the ${ }^{4} \mathrm{He}$ particle (since it also has the longer mean free path in the proportional gas). However, there may also be a contribution from the $0.482 \mathrm{MeV}$ prompt gamma ray decay of the ${ }^{7} \mathrm{Li}$ excited state that could also add to the $>110$ channel region of the spectrum. For the purpose of the study reported here, that gamma ray process was not evaluated.

This paper uses a series of Monte Carlo N-Particle (MCNP) [MCNPX 2011] model calculations to examine the features in the pulse-height spectra resulting from the capture of neutrons in the boron lining of cylindrical proportional counters. The specific model configurations used for this study are described in the Appendix. The objective of those calculations is to demonstrate the 
wall-effect dependence on tube radii and proportional-gas pressure. Also discussed is a how the area of boron lining contained in a set of tubes compares to the area of boron contained in parallel plates.

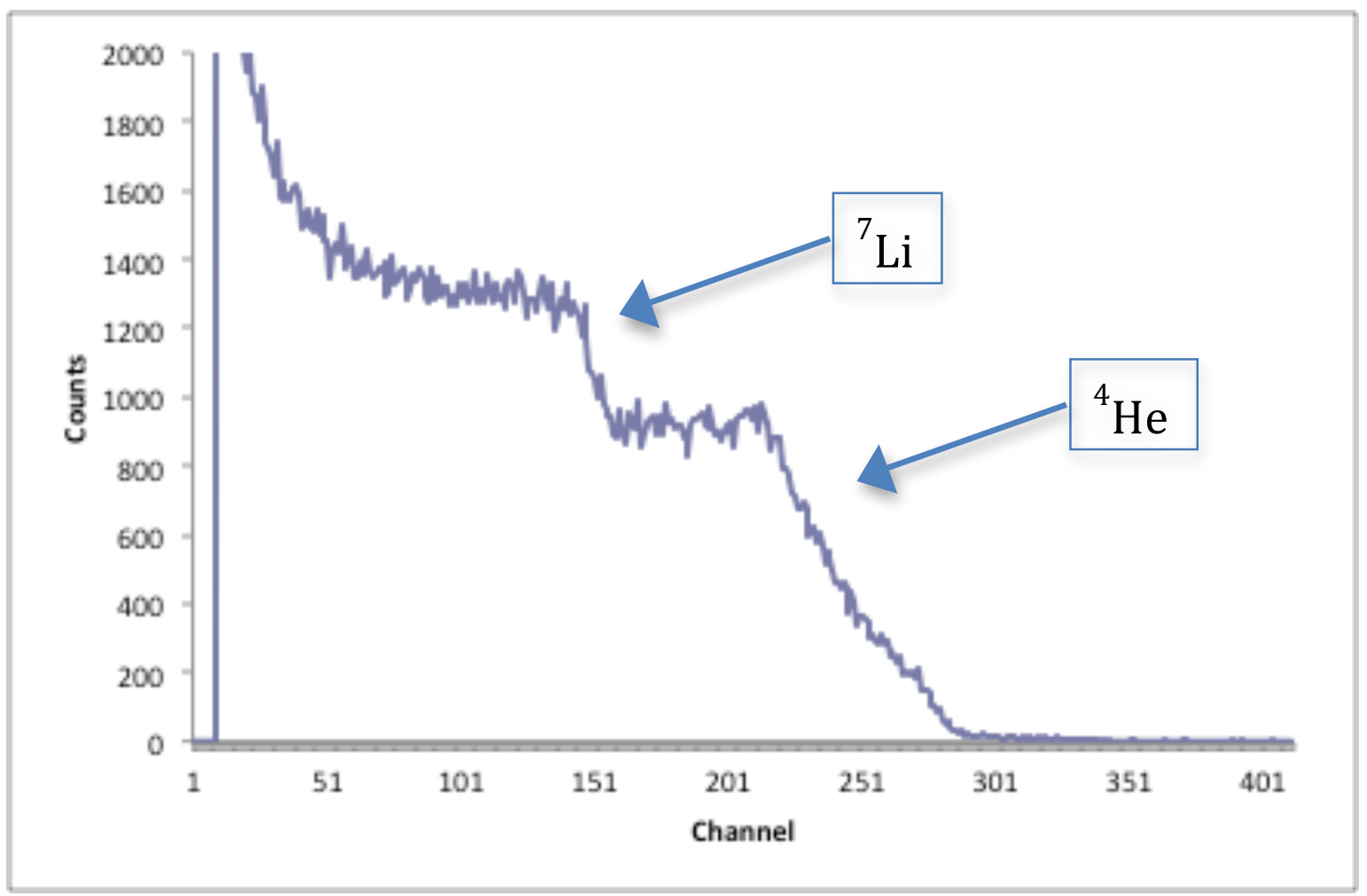

Figure 1.1. Pulse height spectrum from assembly of $2.54 \mathrm{~cm}$ diameter boron-lined counters. 


\section{Model Results for Wall Effects}

To study the effect that tube radii would have on the pulse-height spectra, the MCNPX radiation transport code [MCNPX 2011] was used, and a single-ring-of-tubes configuration was created to represent a typical Neutron Coincidence Counter (NCC) platform for 18 2.54-cm (1-inch) and 14 $5.08-\mathrm{cm}(2-i n c h)$ tubes. Screen captures showing these platforms and how the smaller diameter "tubelets" were distributed in the $5.08 \mathrm{~cm}$ platform are shown and discussed further in the Appendix. Different NCC platforms, tube configurations, or lining thickness, will, of course, affect the absolute values of the total efficiencies of a system. For the purposes of this study, the values obtained from the single-ring NCC configurations described in the Appendix should provide a reasonably accurate baseline for examining the relative effects of tube radii. Similar calculations have been performed in previous modeling studies at PNNL for a wide range of multi-ring, multiplicity-counter configurations of alternative neutron detectors [Ely 2011; Ely 2011b]. The experience and expertise gained from that, and other, PNNL projects in which boron-lined tube modeling was performed is being applied to this project.

Unlike the gas-capture type detectors (e.g., ${ }^{3} \mathrm{He}$ and $\mathrm{BF}_{3}$ ), where the capture material is the same as the signal-generating medium, the detection process with boron-lined tubes involves two steps: the capture of the neutron in the ${ }^{10} \mathrm{~B}$, and then the detection of the reaction products (either the alpha or lithium ion) in the proportional gas. Modeling that process therefore requires tracking both the reaction products from their production and into the gas, with the additional condition that both products were correlated in (opposite) direction when produced. Those capabilities are relatively new additions to MCNPX (version Beta 2.7b) and PNNL was the first to use these capabilities to modeling boron-lined tubes [Siciliano 2010]. The recent version MCNPX 2.7.0 [MCNPX 2011] was used for the evaluations reported here. In addition to providing a more accurate simulation of total count rates, the tracking of the reaction products is important because it allows accurate descriptions of other details for design optimization, such as the boron lining thickness and detector response.

Two types of reaction product tallies are shown in this report. One shows the spectra of the reaction products' incoming currents, and the other shows their pulse-height (PH) spectra. Only the PH spectra are meant to simulate the actual signals measured. The reason for showing the incident currents is that they provide a clear indication of reaction KE positions for the excited state and ground state (94\% and 6\%) branching fractions. Moreover, they are independent of gas pressure; and except for absolute magnitudes (which dependent on the mass of ${ }^{10} \mathrm{~B}$ and geometry), they are essentially identical in shape for all diameter tubes. Finally, they provide a means for seeing the wall effect, in that the degree to which the PH shapes shift from their maximum $\mathrm{KE}$ values indicates the amount that the wall-effect is being experienced by the tube.

As for the pulse-height spectra, they are usually evaluated using the Gaussian energy broadening (GEB) tally treatment. The GEB option in MCNP is provided to better simulate a physical detector in which energy peaks show Gaussian broadening. Typical use of this option has been for approximating the finite resolution in gamma ray spectroscopy, where once its parameters are adjusted; the resulting PH spectra very closely match measured spectra from physical systems. Thus, its use is necessary for the comparison of MCNP calculated spectra with experimental spectra.

The GEB parameters specify the full width at half maximum (FWHM) of the observed energy broadening by the formula: $F W H M(E)=a+b \sqrt{\left(E+c E^{2}\right)}$, where $E$ is the energy of the particle, and the units of $a, b$, and $c$ are $\mathrm{MeV}, \mathrm{MeV}^{1 / 2}$, and $1 / \mathrm{MeV}$, respectively. The parameters $(a, b, c)$ 
used in these simulations had values $(0.0,0.20,0.0)$. The effect of this value upon the reaction $\mathrm{KE}$ fall-offs can be estimated by taking the ratio of the FWHM(E) to one of the KE values. For example, the ${ }^{4} \mathrm{He} \mathrm{KE}$ associated with the ${ }^{7} \mathrm{Li}$ excited state has a $\mathrm{KE}=1.47 \mathrm{MeV}$, and the effect is to spread that drop-off by approximately $8 \%$ to each side.

Note that the GEB tally treatment cannot shift the KE position or change the total count (area) from the PH spectra. Its effect on the simulations reported here is only to smooth the abrupt falloffs, as seen in actual boron lined spectra (e.g., Figure 1.1). To demonstrate the effect the GEB treatment has in the $\mathrm{PH}$ simulations reported here, Figure 2.1 shows pulse heights both with and without using the GEB treatment for one of the Alternative Neutron Coincidence Counter (ANCC) models with $2.54 \mathrm{~cm}$ diameter tubes (see the Appendix for details on the ANCC models). The black line is the total signal arising from the alpha contribution (blue line) and the lithium contribution (green line). The vertical lines are at the four endpoints of the energy distributions corresponding to the ${ }^{4} \mathrm{He}$ and ${ }^{7} \mathrm{Li}$ with the ${ }^{7} \mathrm{Li}$ in the ground or excited state.

The wall effect is due to the ions entering the gas only depositing some of their energy before striking an opposing wall. This wall effect exists in both cylindrical and parallel plate geometries, but is much more pronounced for small cylindrical geometries. The wall effect depends on the tube diameter and the gas pressure. The larger diameter tubes will typically have lower pressure (one third of an atmosphere assumed in the models), while the smaller diameter tubes will typically have higher pressures $(1.0 \mathrm{~atm})$ in order to reduce the wall effect. Lower pressures are used in these proportional counters to reduce the gamma ray sensitivity.

The major question to be answered is whether this wall effect significantly impacts the detectors neutron detection efficiency, or simply distorts the energy spectrum. A lower level discriminator threshold must be applied to the proportional counter signal. For the case of boron-lined counters, the lower level threshold reduces the neutron detection efficiency in an approximately linear fashion with increasing energy since the signal is approximately flat at low energies. This threshold is set to eliminate gamma ray induced signals, and its value is determined by the maximum anticipate gamma ray dose rate (between $10 \mathrm{mR} / \mathrm{h}$ and $1 \mathrm{R} / \mathrm{h}$ ). A threshold of about $100 \mathrm{keV}$ is anticipated.

The top graph in Figure 2.1 shows the computed currents for the total and individual ${ }^{7} \mathrm{Li}$ and ${ }^{4} \mathrm{He}$ currents using an ANCC model. The total current is what would be observed experimentally in an ideal detector. The middle graph shows the pulse heights from the same model with GEB enabled, which broadens the distribution. The wall effect for this model with $1.0 \mathrm{~atm}$ gas pressure only shows a small wall effect as a droop in the curve near the endpoint. The lower graph shows the results for the same model with 0.3 atm gas pressure. At this low pressure, the wall effect is substantial since the higher KE alphas can pass all the way to the opposite wall, thus shifting counts toward lower energy. Even though the wall effect is significant, the counts are simply pushed to lower in the spectrum, and the total number of counts above the low energy threshold of about $100 \mathrm{keV}$ remains the same for this tube diameter. 


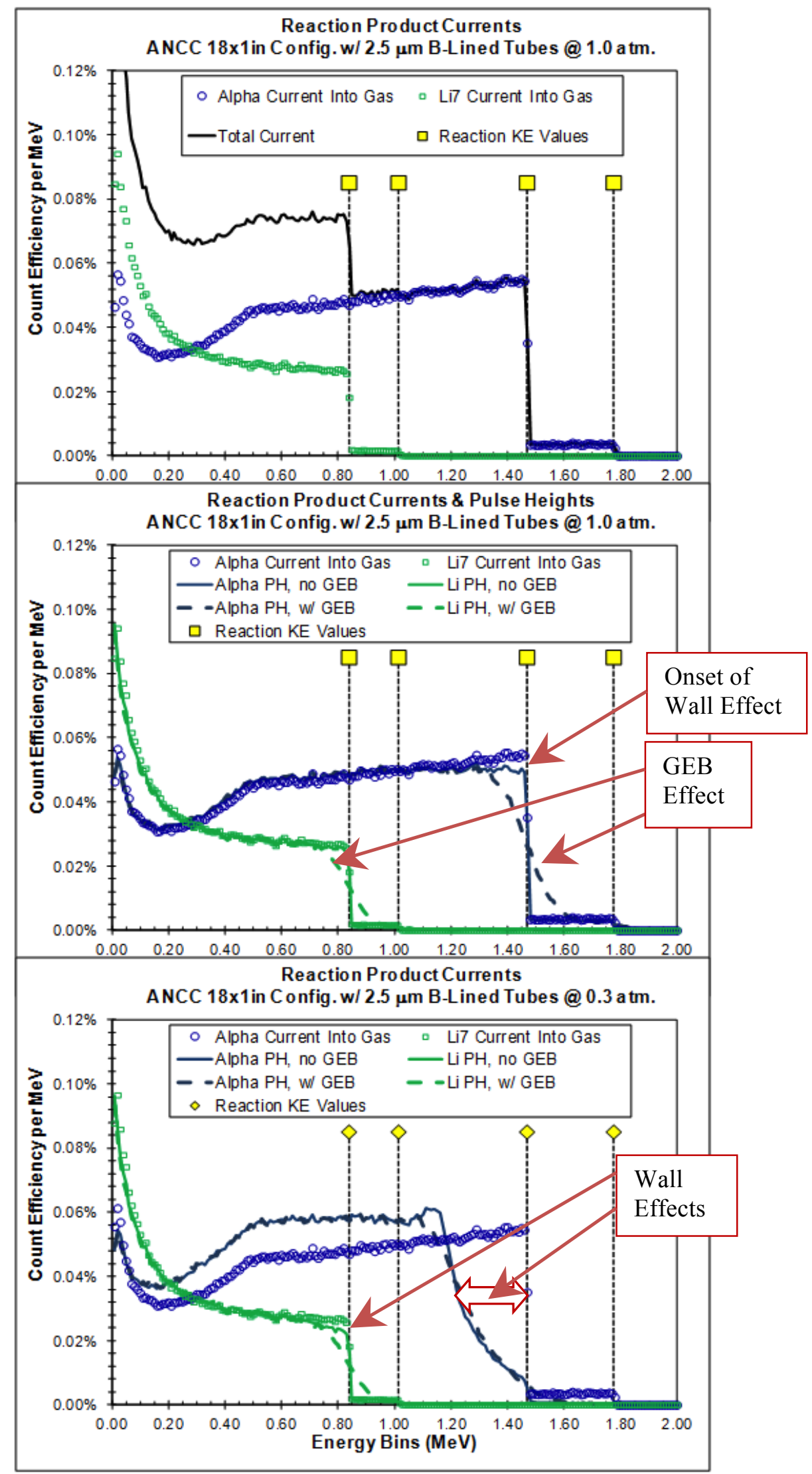

Figure 2.1. Currents and pulse heights from $2.54 \mathrm{~cm}$ tubes showing GEB and wall effects. 


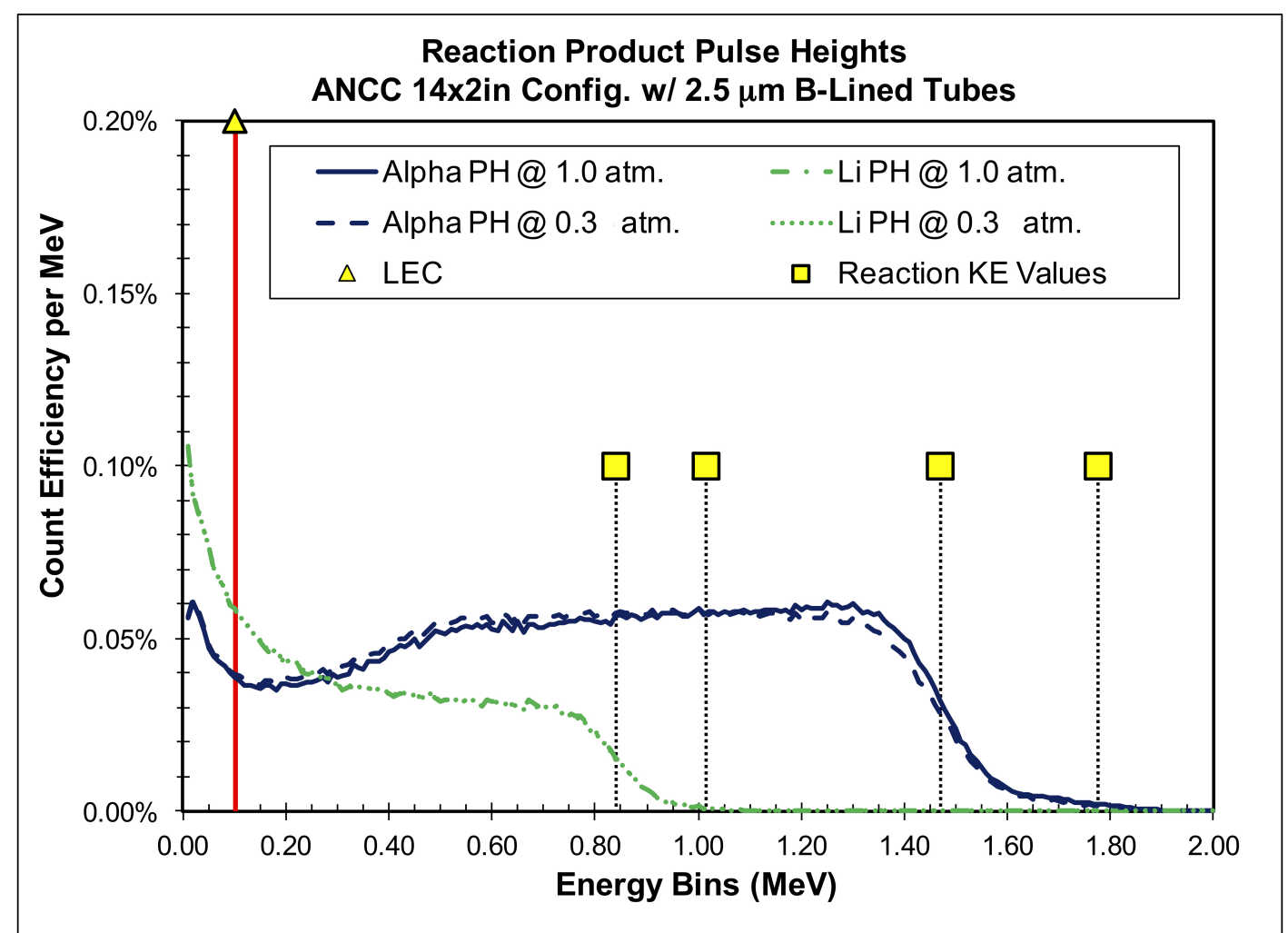

Figure 2.2. Energy deposited from array of $5.08 \mathrm{~cm}$ diameter boron-lined tubes.

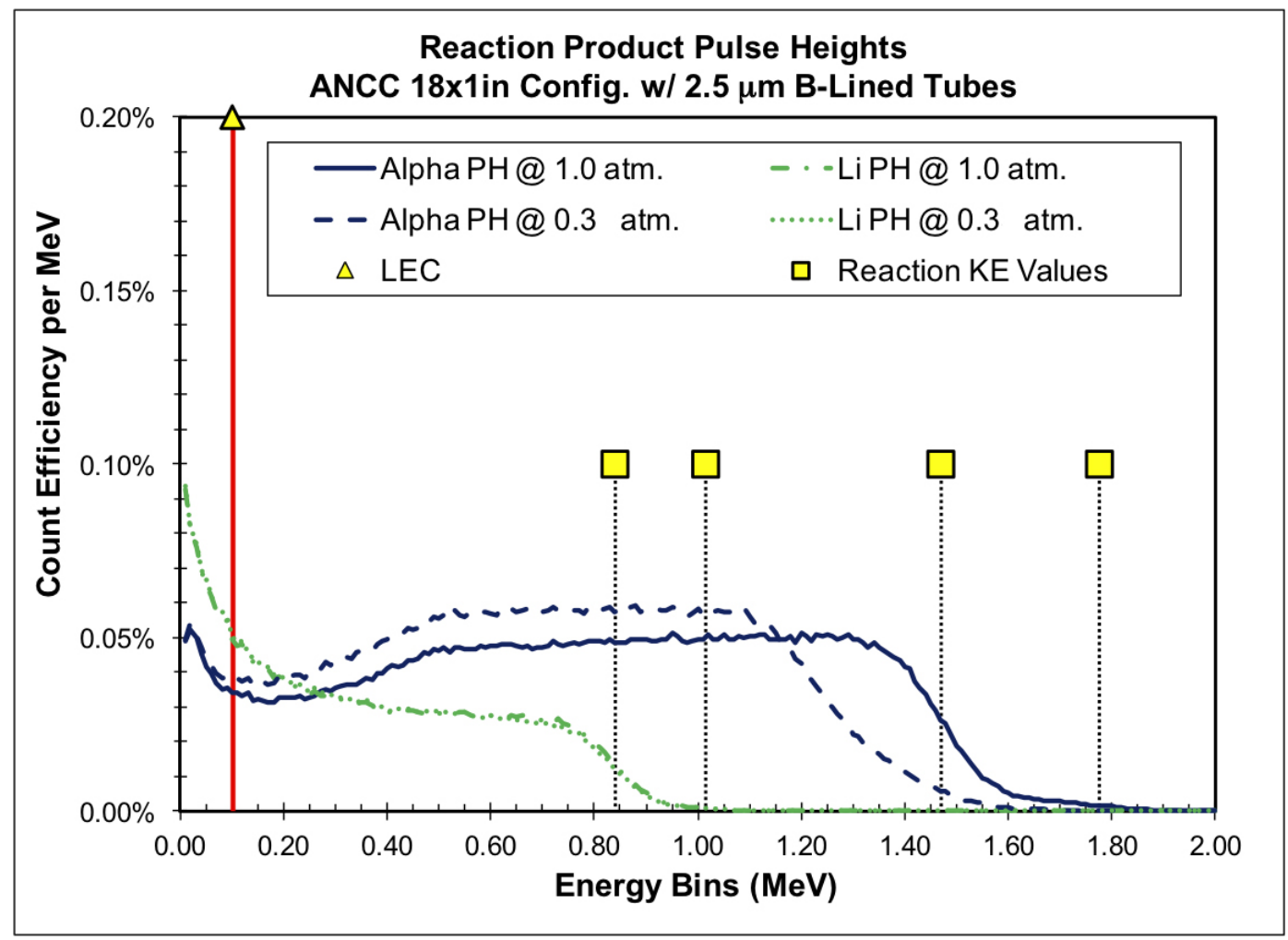

Figure 2.3. Energy deposited from array of $2.54 \mathrm{~cm}$ diameter boron-lined tubes. 
Figure 2.2 shows the model results for the pulse height in an assembly of 14 boron-lined tubes with a $5.08 \mathrm{~cm}$ diameter and pressures of 1.0 and $0.3 \mathrm{~atm}$. A slight wall effect is seen at the lower pressure as the difference between the two curves for the alpha pulse height.

Figure 2.3 similarly shows the results for an assembly of 18 boron-lined tubes (see Appendix) with a $2.54 \mathrm{~cm}$ diameter. The wall effect for the alpha signal is significant at the lower pressure. A very small number of counts are lost below the threshold of $100 \mathrm{keV}$, as discussed later.

Figure 2.4 shows the results for an array of $14 \times 7$ boron-lined tubes (see Appendix) with a 1.27 $\mathrm{cm}$ diameter. The wall effect is very significant at the lower pressure for the alpha particle signal, and a small impact on the ${ }^{7} \mathrm{Li}$ signal is seen. A small number of counts are lost below the threshold of $100 \mathrm{keV}$, as discussed later.

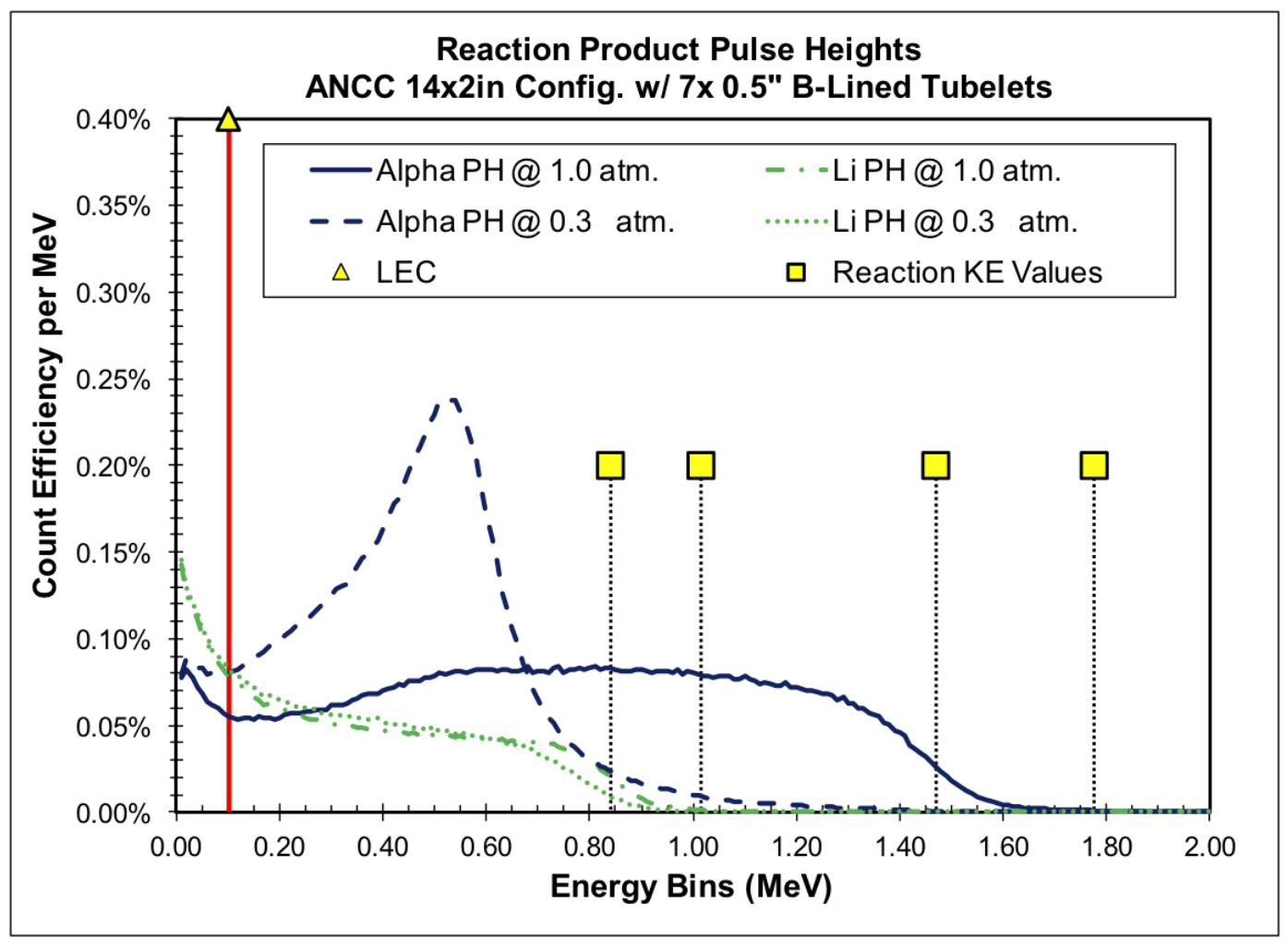

Figure 2.4. Energy deposited from array of $1.27-\mathrm{cm}$ diameter boron-lined tubelets.

Figure 2.5 shows the results for an array of 14x19 boron-lined tubes (see Appendix) with an 8 $\mathrm{mm}$ diameter. The wall effect is substantial at both pressures for the alpha particle signal, and an impact on the ${ }^{7} \mathrm{Li}$ signal is seen. Some counts are lost below the threshold of $100 \mathrm{keV}$. It should be noted that vendors tend to use pressures close to one atmosphere for these smaller tubes.

Figure 2.6 shows the results for an array of 14x50 boron-lined tubes (see Appendix) with a $4 \mathrm{~mm}$ diameter. The wall effect is substantial at both pressures for both the alpha particle and the ${ }^{7} \mathrm{Li}$ signal. Counts are lost below the threshold of $100 \mathrm{keV}$. As for the $8 \mathrm{~mm}$ tubes, vendors tend to use pressures close to one atmosphere for these tubes. 


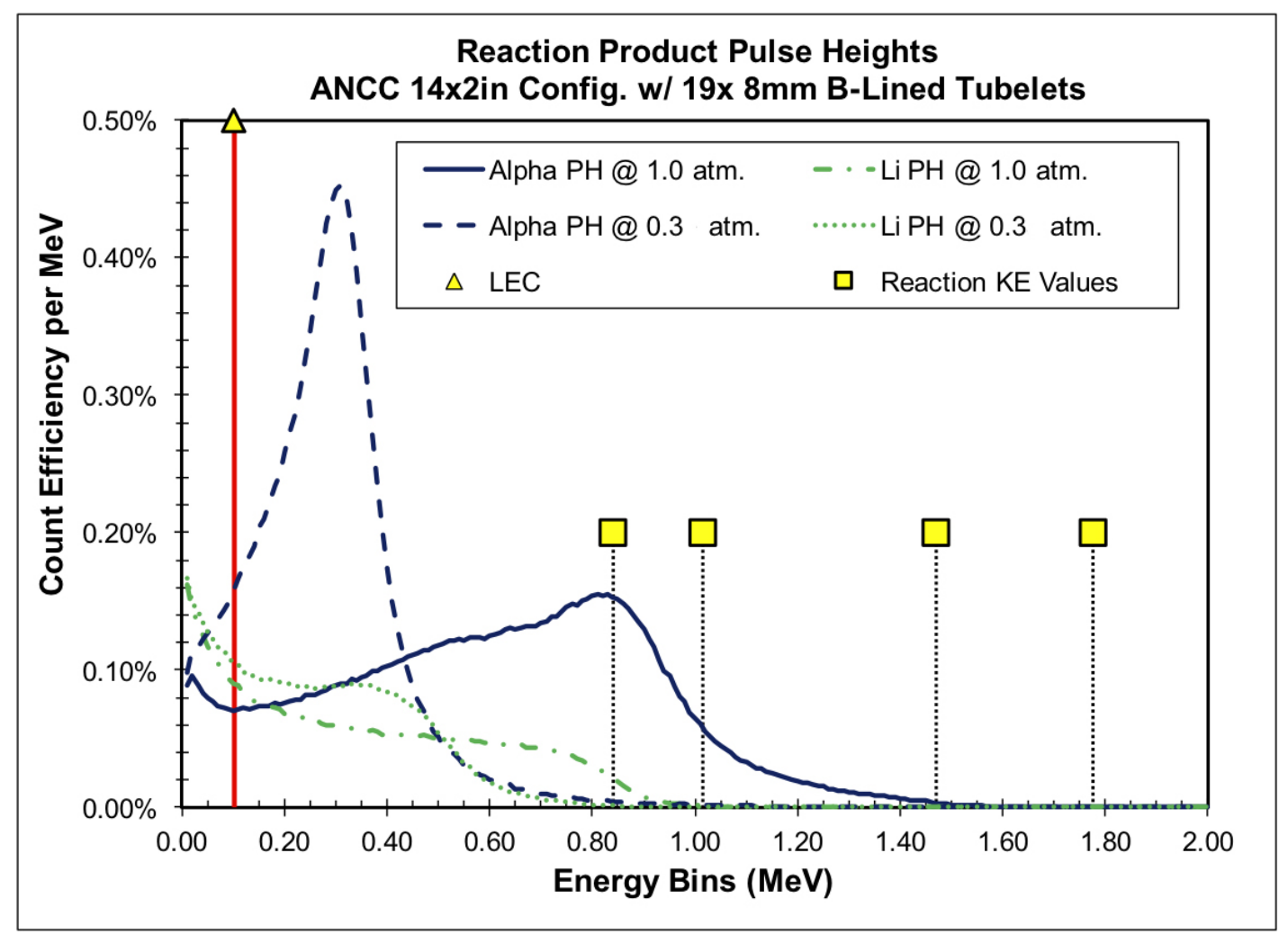

Figure 2.5. Energy deposited from array of 8-mm diameter boron-lined tubelets.

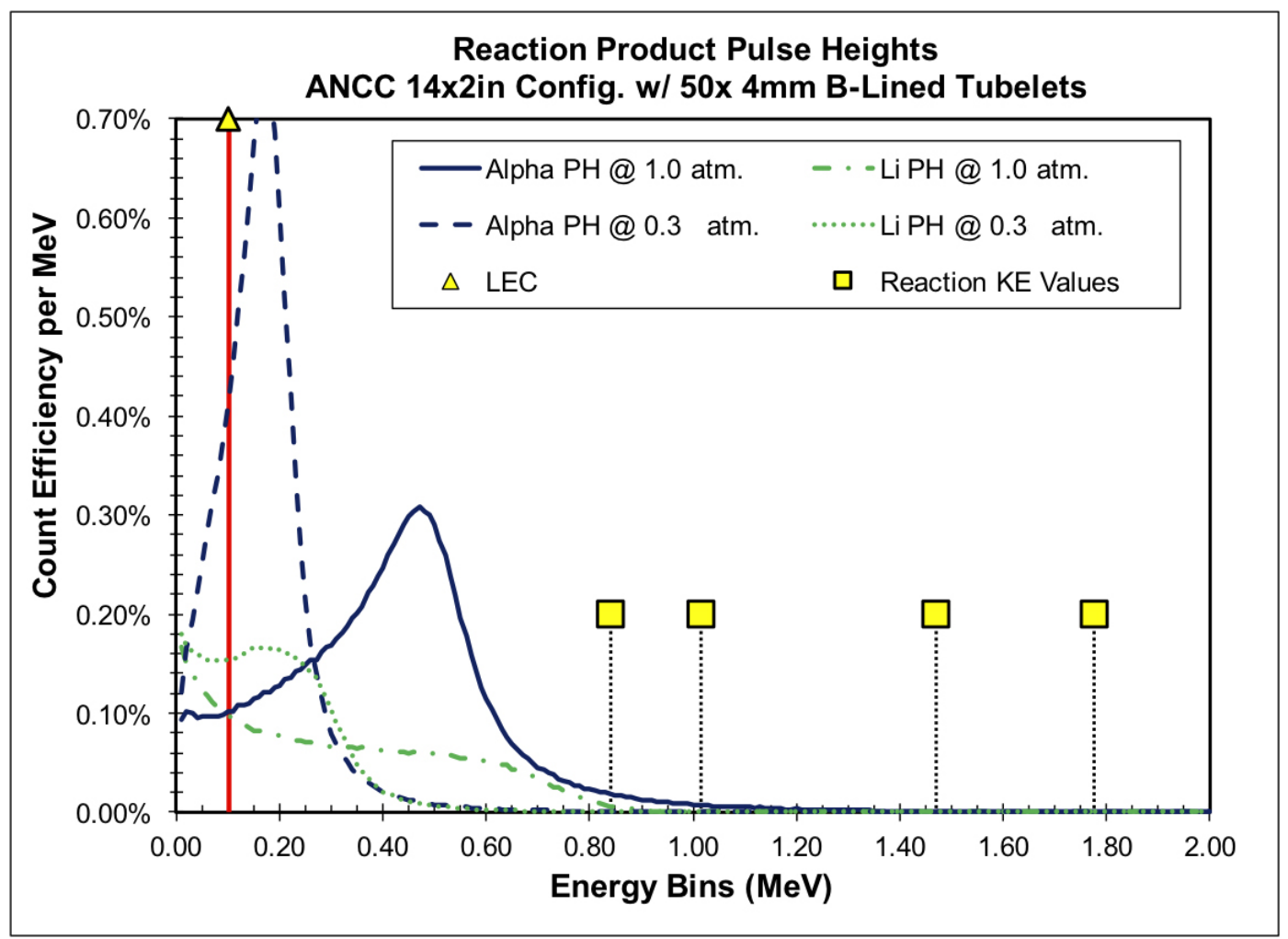

Figure 2.6. Energy deposited from array of 4-mm diameter boron-lined tubelets. 
Figure 2.7 shows a summary of the total signal seen for each of the five different diameter tubes with a gas pressure of one atmosphere. At this pressure, some counts are lost below the low energy cuttoff threshold for the smaller radii, though not a substantial fraction. Figure 2.8 shows a similar summary of the total signal for each of the five different diameter tubes with a gas pressure of 0.3 atmosphere. Here, the efficiency of the small diameter tubes is significantly impacted.

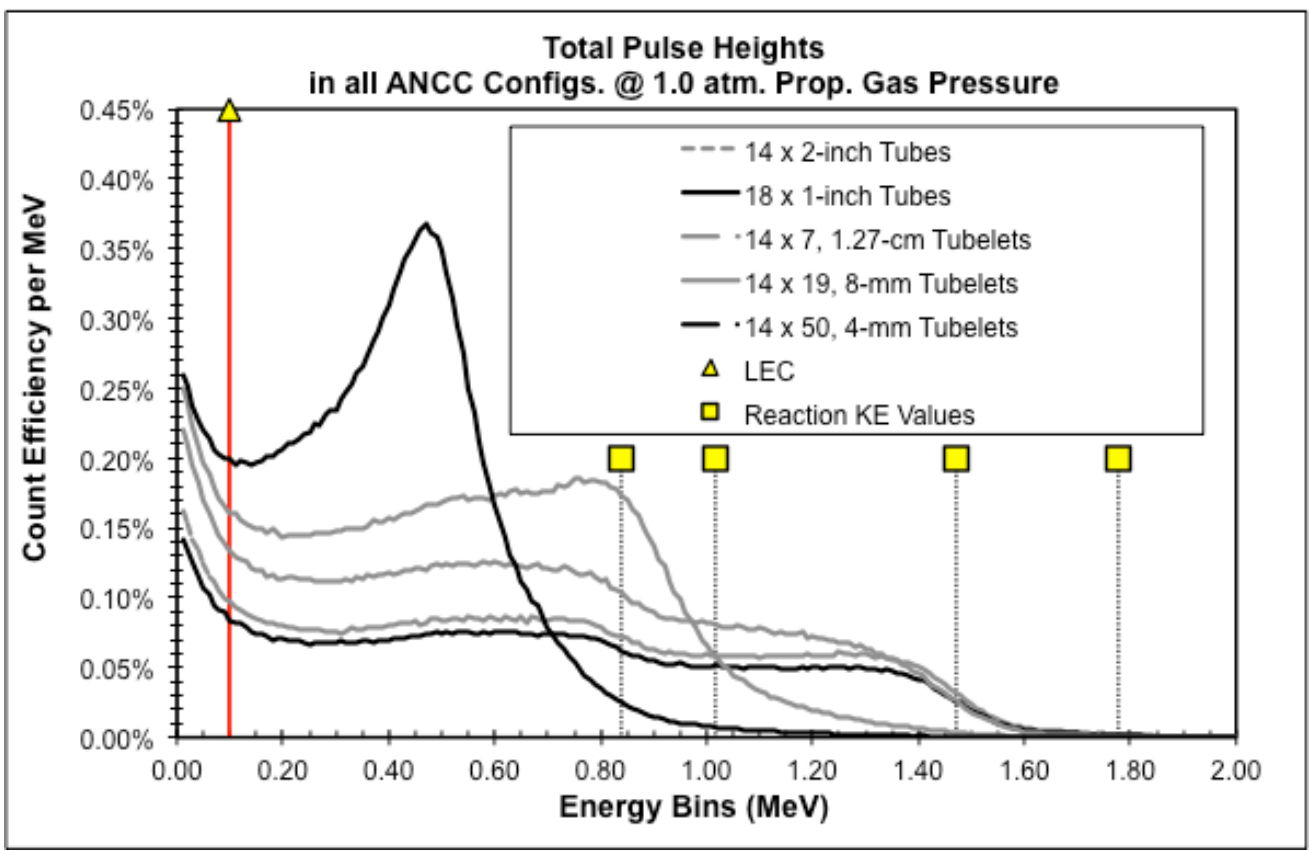

Figure 2.7. Total Pulse-Height Comparisons for 1.0-atm gas pressure.

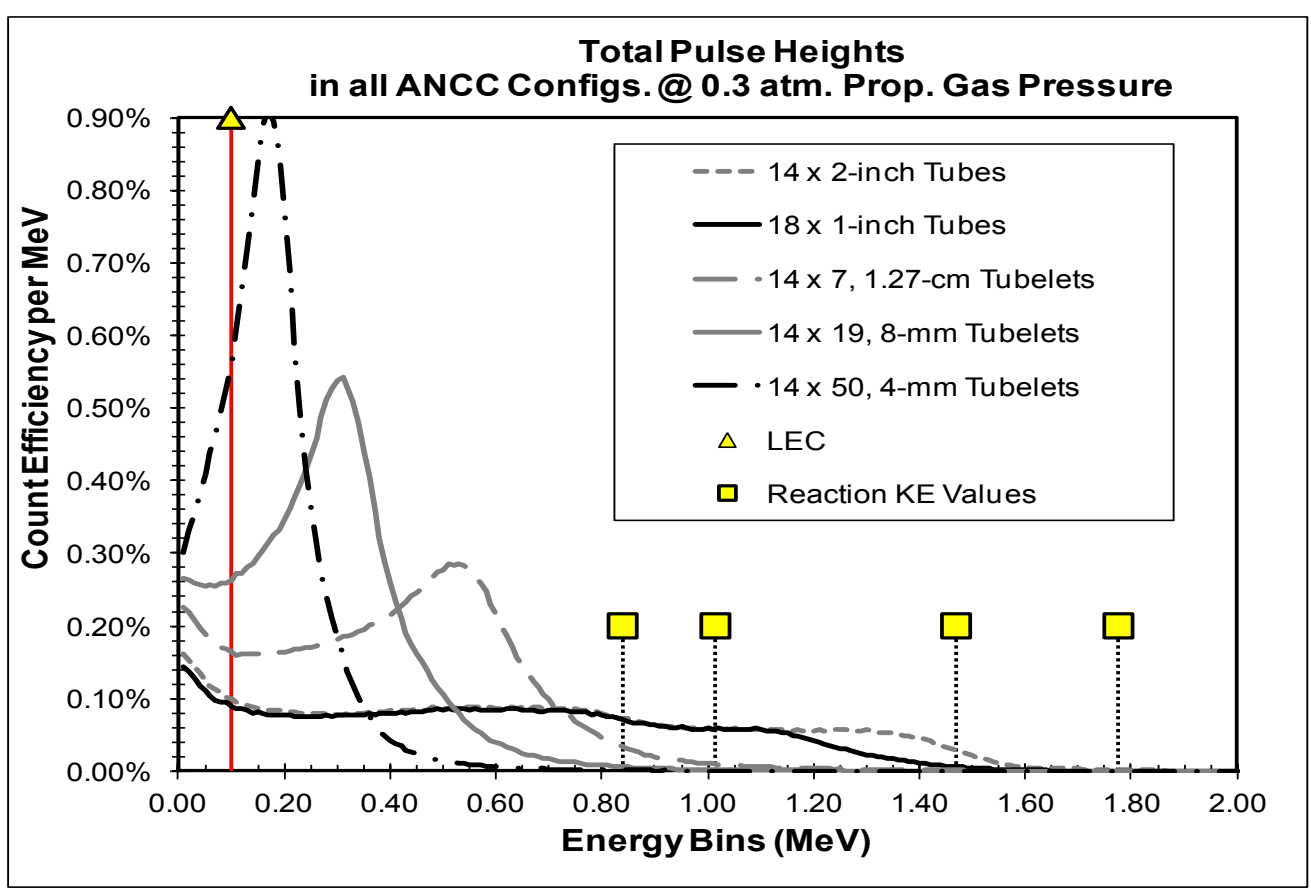

Figure 2.8. Total Pulse-Height Comparisons for 0.3-atm gas pressure 
An evaluation was made of the impact on efficiency of the tubes as a function of the low energy cutoff threshold. The threshold will probably differ with tube diameter since the gas pressure used will differ, impacting the gamma ray sensitivity. Plots are shown of relative efficiency. Comparisons of absolute efficiency depend on the full geometry used and are thus beyond the scope of this paper, but are discussed elsewhere [Ely 2011b].

Figure 2.9 shows the dependence of percentage of counts above threshold versus threshold value in $5.08 \mathrm{~cm}$ diameter boron-lined tubes for both 1.0 and 0.3 atm gas pressure. It can be seen that the efficiency is fairly linear with threshold value and that there is only a slight difference between the two gas pressures. An efficiency of $\sim 90 \%$ of the total counts should be possible with a threshold at $100 \mathrm{keV}$.

Figure 2.10 shows the dependence of percentage of counts above threshold versus threshold value in $2.54 \mathrm{~cm}$ diameter boron-lined tubes for both 1.0 and $0.3 \mathrm{~atm}$ gas pressure. Some difference is seen in efficiency above a threshold of about $300 \mathrm{keV}$ for the two pressures.

Figure 2.11 shows the dependence of percentage of counts above threshold versus threshold value in $1.27 \mathrm{~cm}$ diameter boron-lined tubes for both 1.0 and $0.3 \mathrm{~atm}$ gas pressure. A large difference in efficiency is seen above a threshold of about $200 \mathrm{keV}$ for the two pressures.

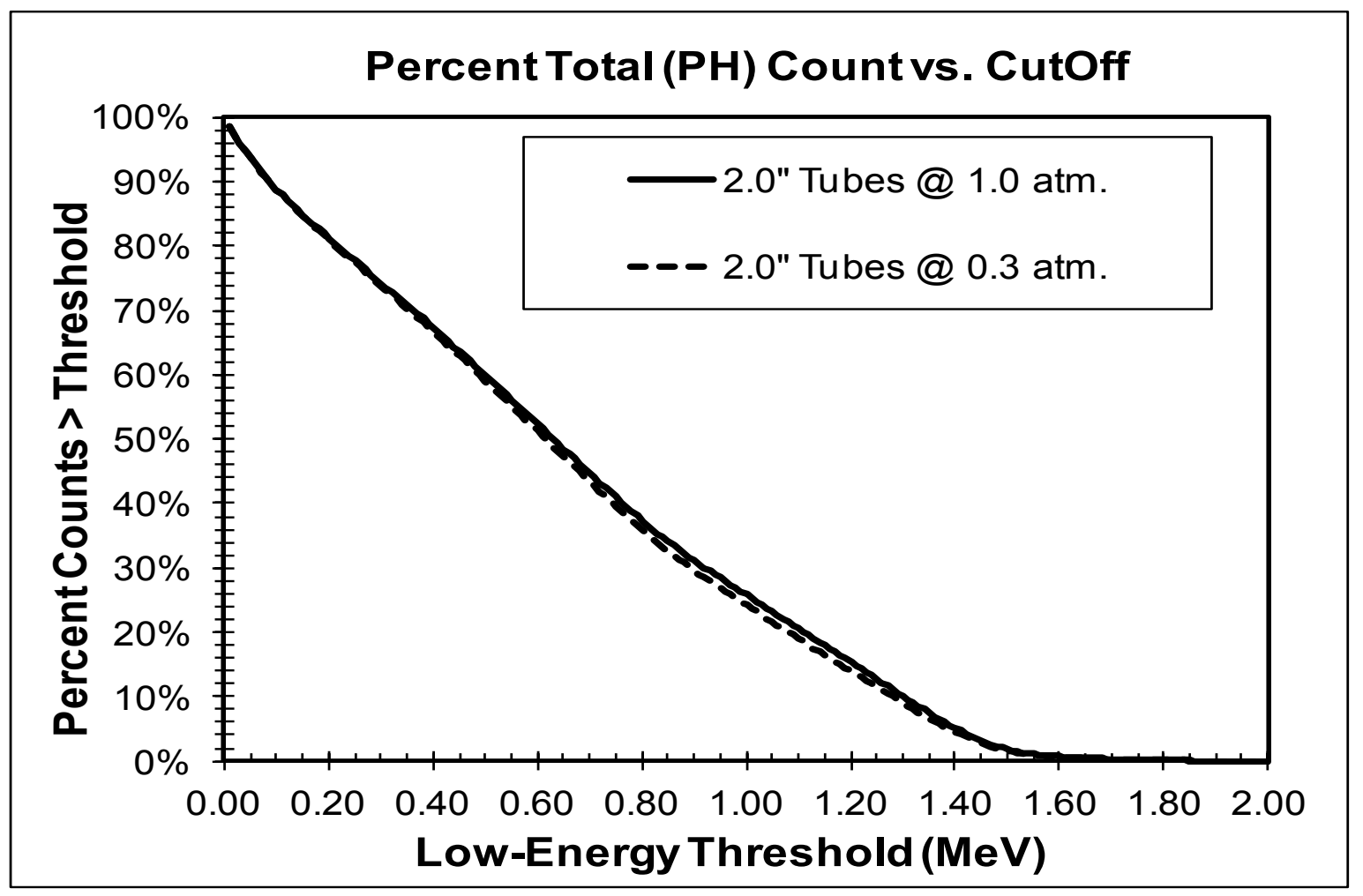

Figure 2.9. Loss of counts as function of LEC for 14, 5.08-cm diameter tubes. 


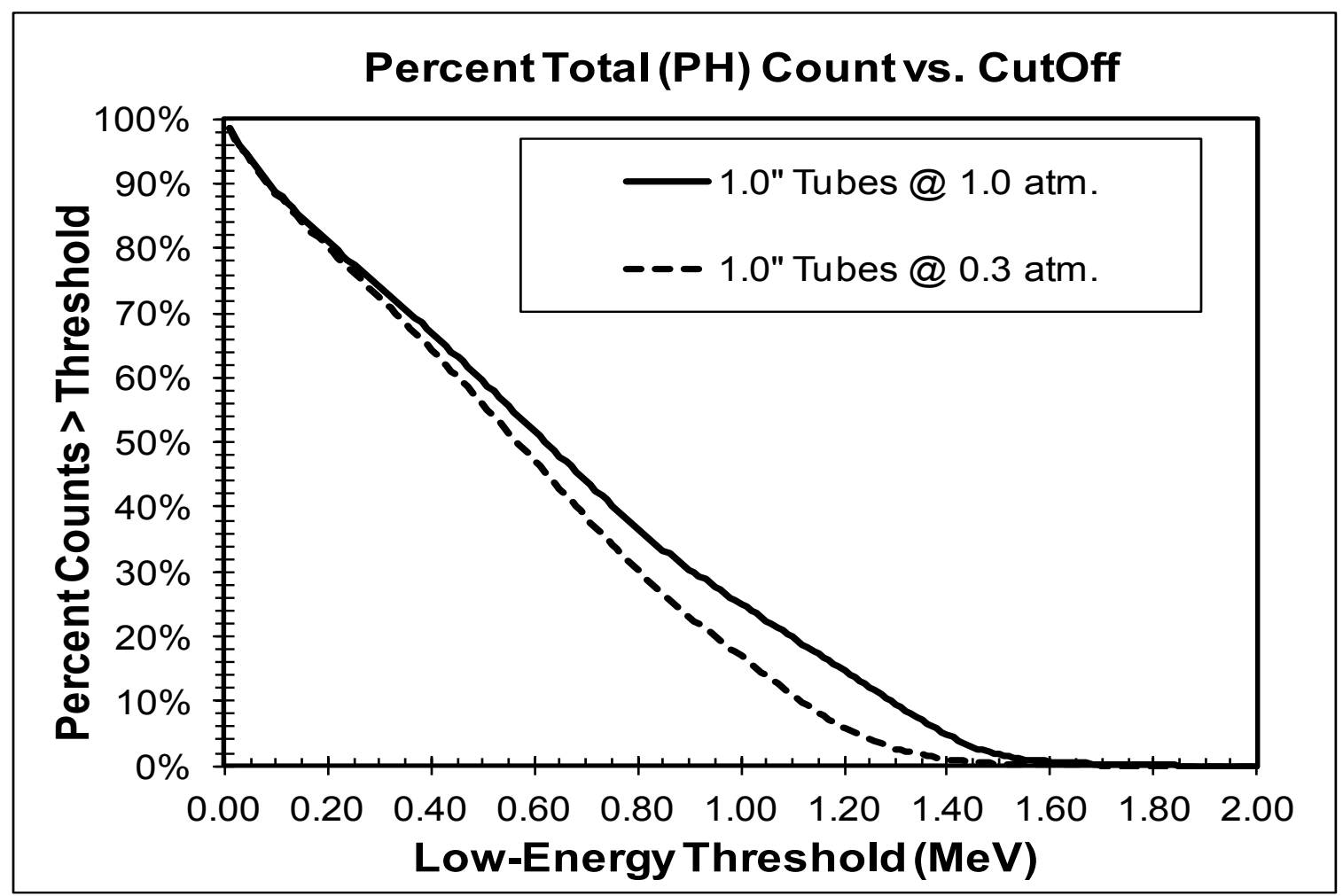

Figure 2.10. Loss of counts as function of LEC for 18, 2.54-cm diameter tubes.

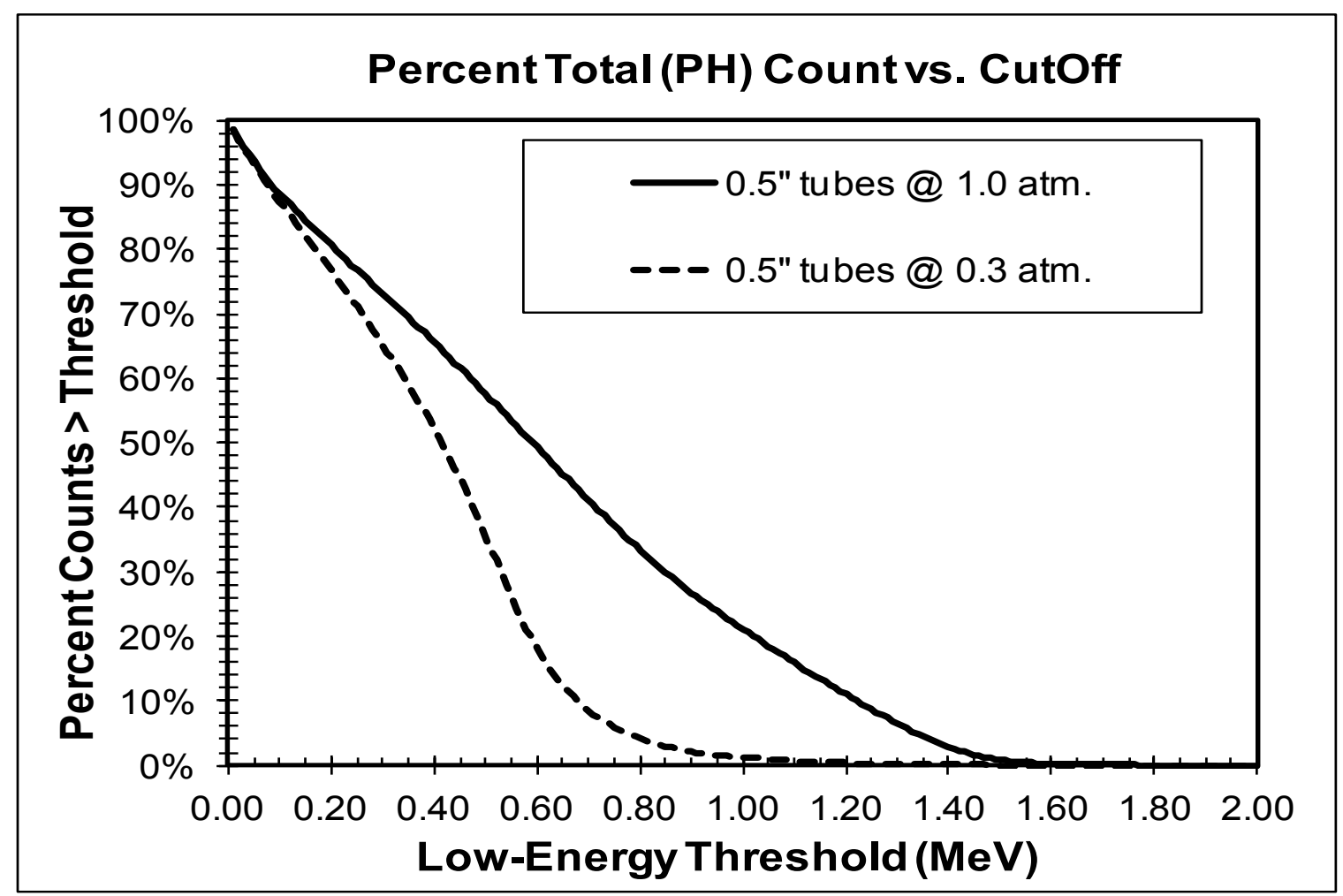

Figure 2.11. Loss of counts as function of $L E C$ for $14 \times 7,1.27-\mathrm{cm}$ diameter tubelets. 
Figure 2.12 shows the dependence of percentage of counts above threshold versus threshold value in $8 \mathrm{~mm}$ diameter boron-lined tubes for both 1.0 and $0.3 \mathrm{~atm}$ gas pressure. A large difference in efficiency is seen above a threshold of about $100 \mathrm{keV}$ for the two pressures. However, vendors typically do not use such low pressures for the smaller diameter tubes.

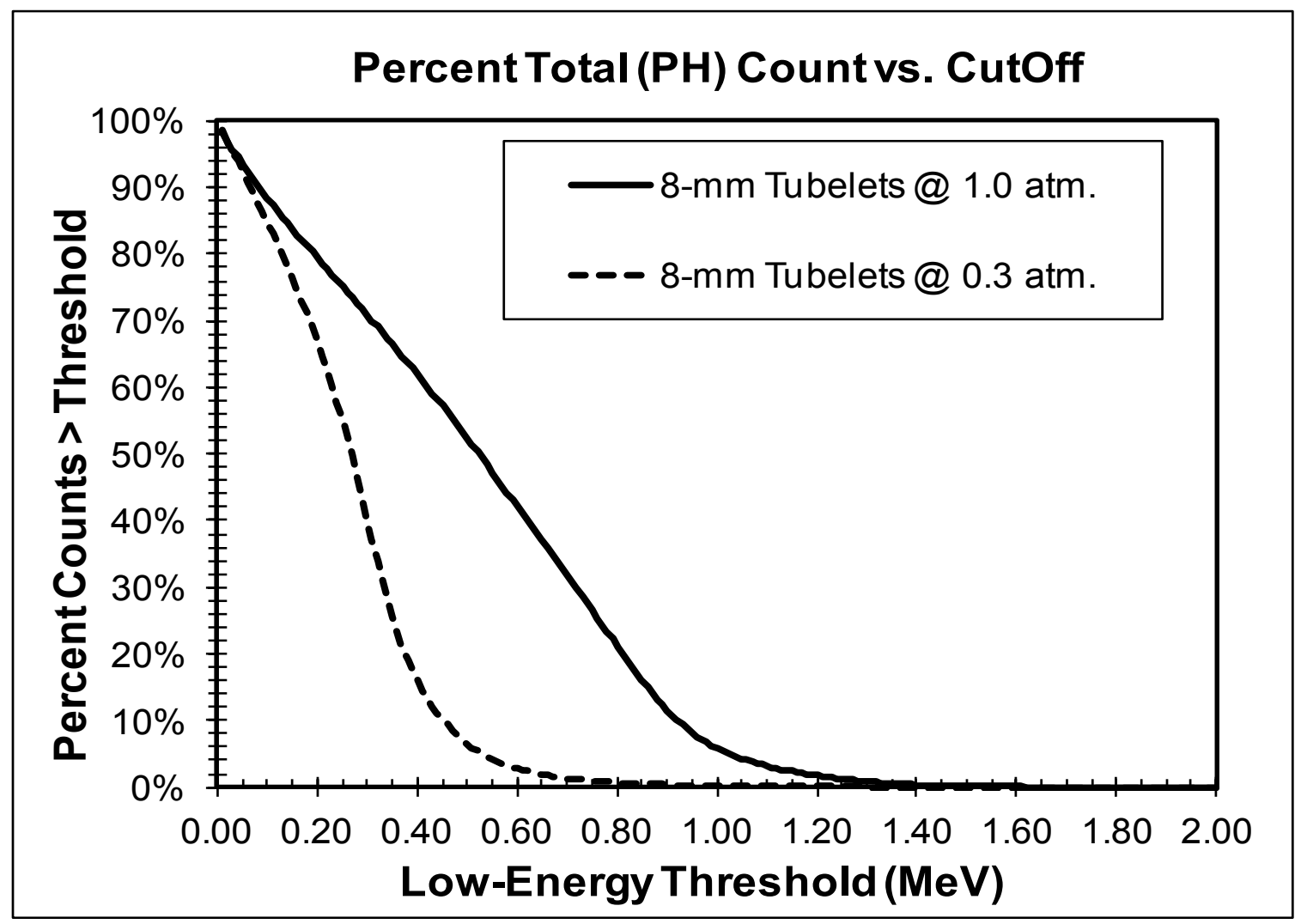

Figure 2.12. Loss of counts as function of LEC for 14x19, 8-mm diameter tubelets.

Figure 2.13 shows the dependence of percentage of counts above threshold versus threshold value in $4 \mathrm{~mm}$ diameter boron-lined tubes for both 1.0 and $0.3 \mathrm{~atm}$ gas pressure. A large difference in efficiency is seen above a threshold of about $50 \mathrm{keV}$ for the two pressures. However, vendors typically do not use such low pressures for the smaller diameter tubes.

In summary, the wall effect depends on both tube diameter and gas pressure. Significant wall effects are shown in the model for the small tube diameters (4 and $8 \mathrm{~mm}$ ). However, for all tube diameters, the loss of efficiency due to the wall effect is small when the appropriate pressure is used. This results from the fact that, while the spectrum may be significantly distorted by the wall effect, the counts are not lost below the low energy threshold. For all size tubes, there is an uncertainty in the tube efficiency if the threshold (or gain) is not stable due to the linear dependence of the total counts versus threshold. 


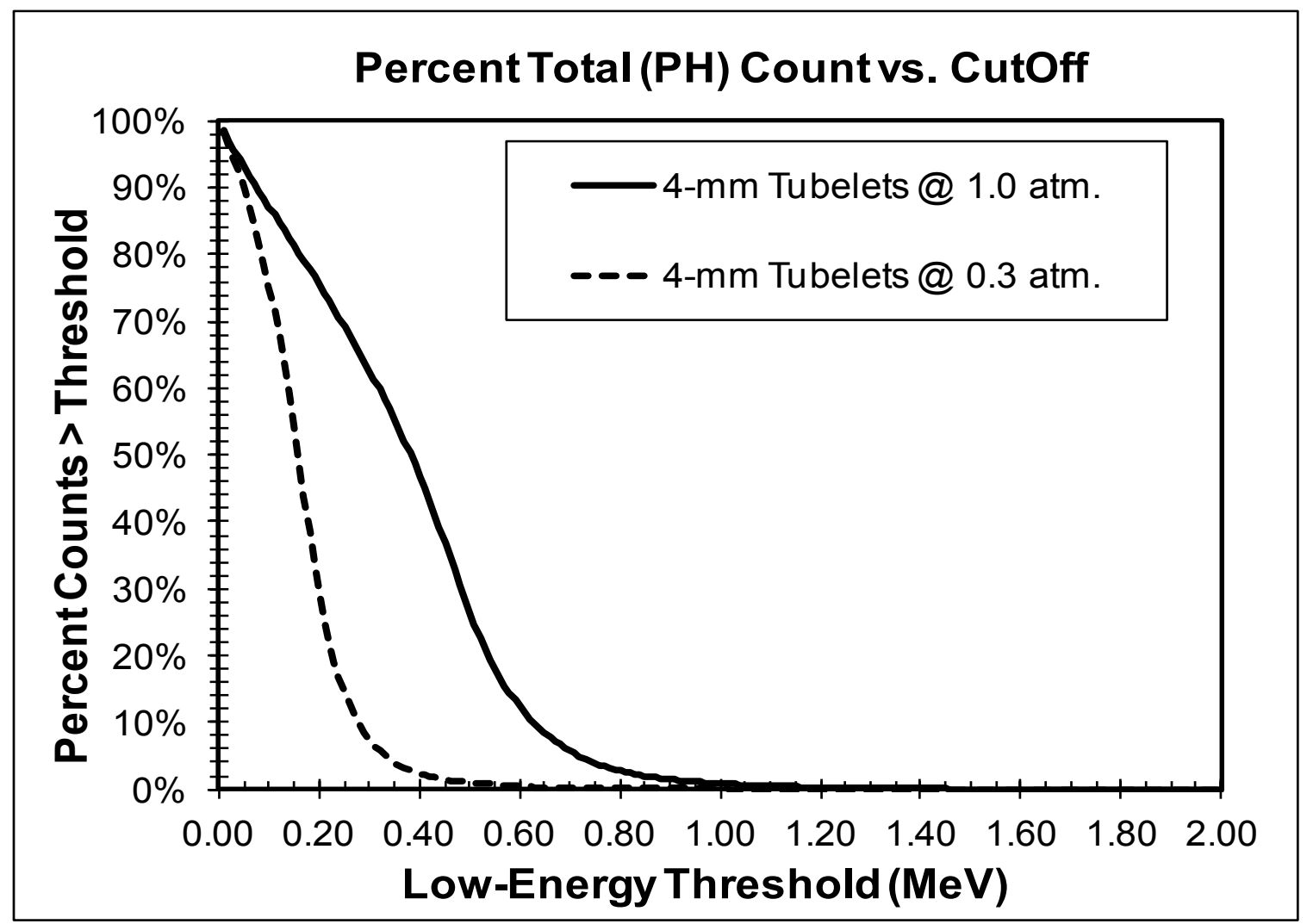

Figure 2.13. Loss of counts as function of LEC for 14x50, 4-mm diameter tubelets 


\section{Parallel Plate Compared to Cylindrical Counters}

Multi-wire parallel plate geometries are also under consideration as alternative neutron detectors (e.g., system manufactured by Precision Data Technology) [Henzlova 2012]. These systems have planes of wires between two metal plates covered with a ${ }^{10} \mathrm{~B}$ compound. The plate spacing determines the number of proportional wires required, with more wires as the plates are brought closer together. The gas used, and its pressure, determine the minimum plate spacing. Wall effects come to play in parallel plate systems as the plates are brought closer together to increase the total density of ${ }^{10} \mathrm{~B}$, but the effect is less since particles have more room to traverse parallel to the plates.

A related question to the effect of tube size on efficiency is the total efficiency of a system using tubes versus one using parallel plates. This is highly dependent on the geometry used. For example, consider a scenario where $\mathrm{N}$ tubes of radius $\mathrm{R}$ and length $\mathrm{L}$ are lined up in a row and are touching, as seen in Figure 3.1. The boron lining surface area on the inside of these tubes is thus $(2 \pi \mathrm{R}) \mathrm{LN}$. This can be compared to the parallel plate case (Figure 3.2) with the same spacing and length of $2(2 \mathrm{RLN})$. Thus, the cylinders have $\pi / 2$, or $57 \%$, more boron than the parallel plates.

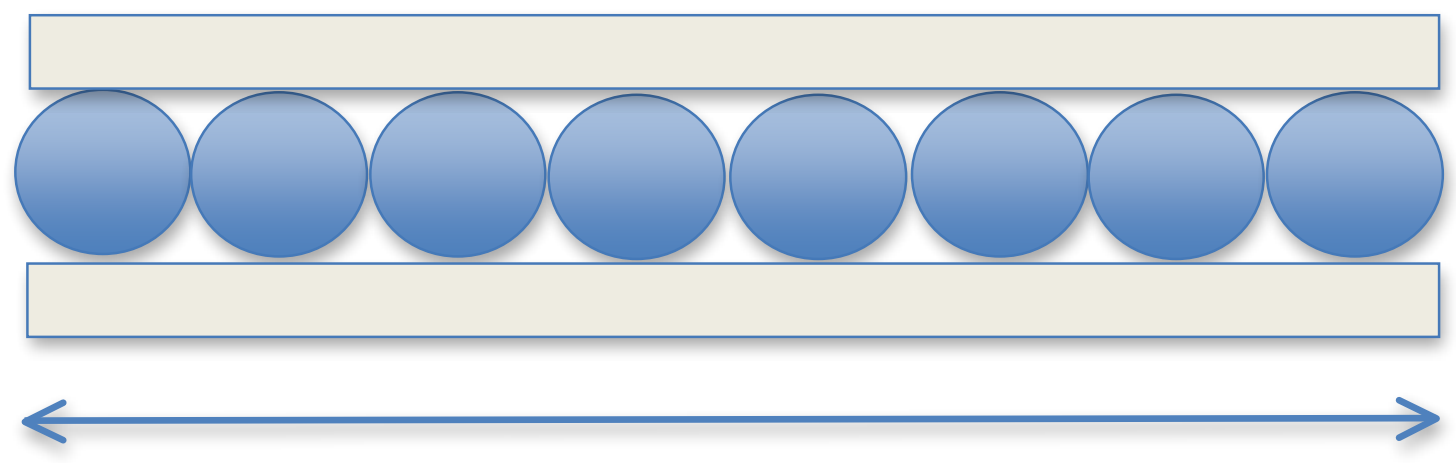

Figure 3.1. Multi-tube configuration seen from the end.
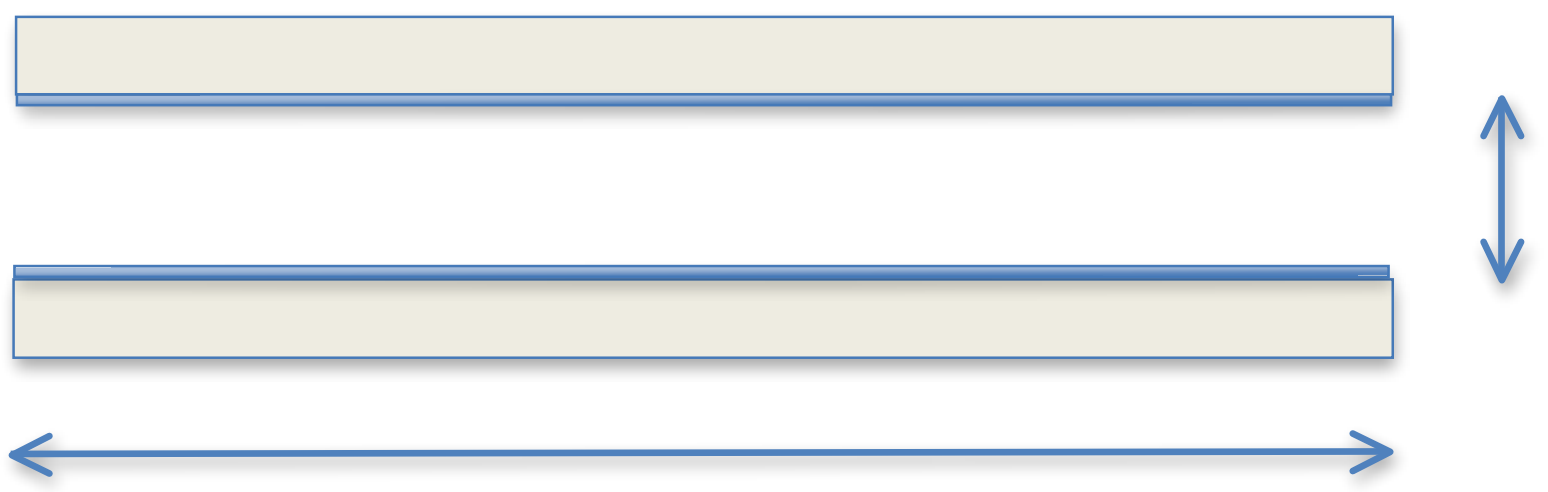

Figure 3.2. Parallel plate configuration seen from the end. 
In order for parallel plates to have an equal surface area of boron, multiple parallel plates must be used and they must be spaced at closer than $2 \mathrm{R}$. If there are $\mathrm{C}$ rows of tubes of radius $\mathrm{R}$, and $\mathrm{P}$ rows of parallel plates of any spacing, then to have an equal amount of boron:

$$
2 \pi \mathrm{RLNC}=4 \mathrm{RLNP}
$$

or $\mathrm{P}=\pi \mathrm{C} / 2$. For example, if $\mathrm{C}=5$ rows, then $\mathrm{P} \cong 8$ rows, or $57 \%$ more rows.

Alternately, the tubes might be spaced apart, as seen in Figure 3.3. Again, there would be 57\% fewer tubes to obtain the same amount of boron surface area. If the tubes are at least $8 \mathrm{~mm}$ in diameter, there would be no wall losses of efficiency, and tube systems and parallel plate systems would have the same efficiency if all other effects can be ignored (which they probably cannot). What this does imply is that there is flexibility in either a tube or parallel plate implementations of a coincidence counter, and modeling will be needed to determine which approach is best with regard to simplicity and cost of construction.
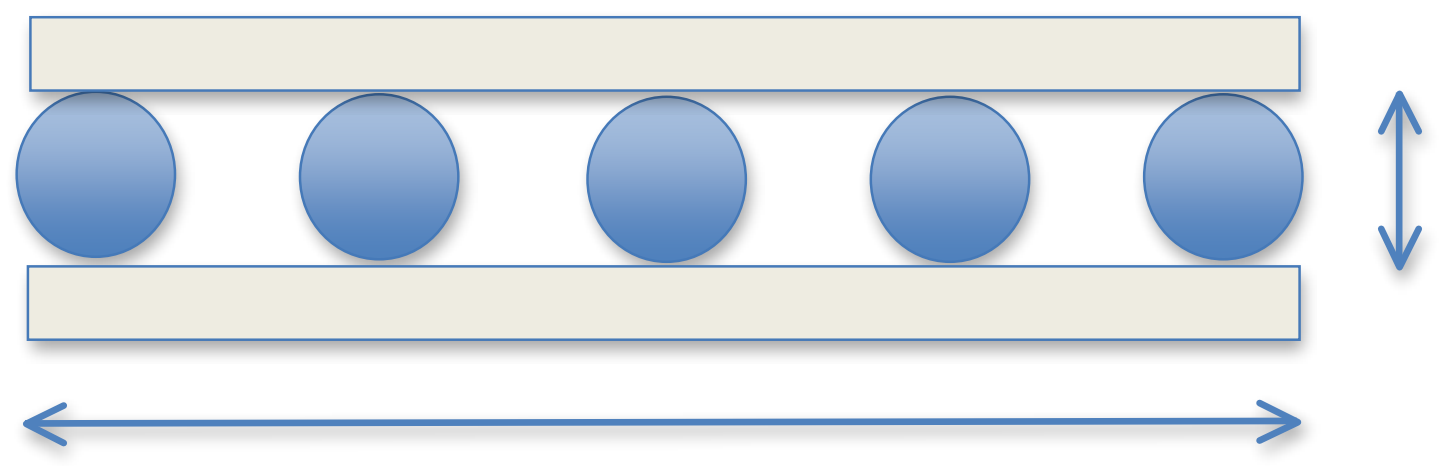

Figure 3.3. Parallel plate configuration seen from the end. 


\section{Conclusions}

This report examined the impact that tube radius and gas pressure is expected to have on the efficiency of cylindrical proportional tubes in neutron coincidence counters. The loss of signal amplitude due to ions hitting the opposite wall before losing all of their energy is seen for tubes of radius smaller than $2.54 \mathrm{~cm}$, but since the signal does not significantly fall below the threshold until the radius is about $4 \mathrm{~mm}$, there is little impact on the total efficiency. The simulations also show that the stability of the threshold (and gain) is important to maintaining constant efficiency since the observed total counts depends linearly on the threshold value. It is shown that parallel plate geometries require about $57 \%$ more active surface area (i.e., more layers) in order to have equal efficiency to rows of cylindrical tubes. 


\section{Appendix}

The numerical results presented in this paper were obtained by using existing multi-tube models of an alternative neutron coincidence counter (ANCC). This appendix gives a brief description of those models.

Two, slightly different ANCC model "platforms" were used to evaluate the five different sized tubes studied in this report. Cross sectional views (screen captures) of these are shown, to-scale, above in Figure 5.1. All are polyethylene-filled (light blue) cylinders of the same $80-\mathrm{cm}$ height and sample chamber (dark blue) diameter of $16.6 \mathrm{~cm}$. All have the same thin sample-chamber liner shells of $\mathrm{Al}$ and $\mathrm{Cd}$; and the same Cd-lined top and bottom graphite plugs. All use the same $71.12-\mathrm{cm}$ active heights for the tubes and $100 \%$ argon as the proportional gas fill. All use the same 2.5 micron-thick lining of $100 \%$ (solid) ${ }^{10} \mathrm{~B}$.

Shown in the upper left corner of Figure 5.1 is the starting or reference configuration. It has the overall diameter of $40 \mathrm{~cm}$ and contains $18,2.54-\mathrm{cm}$ diameter ${ }^{10} \mathrm{~B}$-lined tubes. Shown in the upper right, middle left and right, and lower left is the other, slightly larger platform of $45 \mathrm{~cm}$. It was enlarged to accommodate the other four configurations of boron-lined tubes, while keeping the amount of moderation between the sample chamber and tubes approximately equal. The upper right is the configuration used for the 14 boron-lined $5.08-\mathrm{cm}$ diameter tubes. The middle left and right show how this same configuration was used to evaluate the $1.27-\mathrm{cm}$ and $8.0-\mathrm{mm}$ cases of boron-lined tubes, by removing the ${ }^{10} \mathrm{~B}$ lining from the outer, 5.08-cm shell and adding it to the lattice of 7 or 19 smaller "tubelets" contained within the $5.08-\mathrm{cm}$ cylinder. Because there are still $145.08-\mathrm{cm}$ cylinders, these cases have a total of 98 and 266 tubelets, respectively. Using the same platform, but changing from a 5.08-cm cylinder to a $5.08 \times 2.45$ rectangle, the lower two frames in the figure show the configuration used to evaluate the 4-mm boron-lined tubes. Note that each rectangular shell contained 50 tubes, and there are 14 of them, giving a total of 700 tubelets in that configuration. 


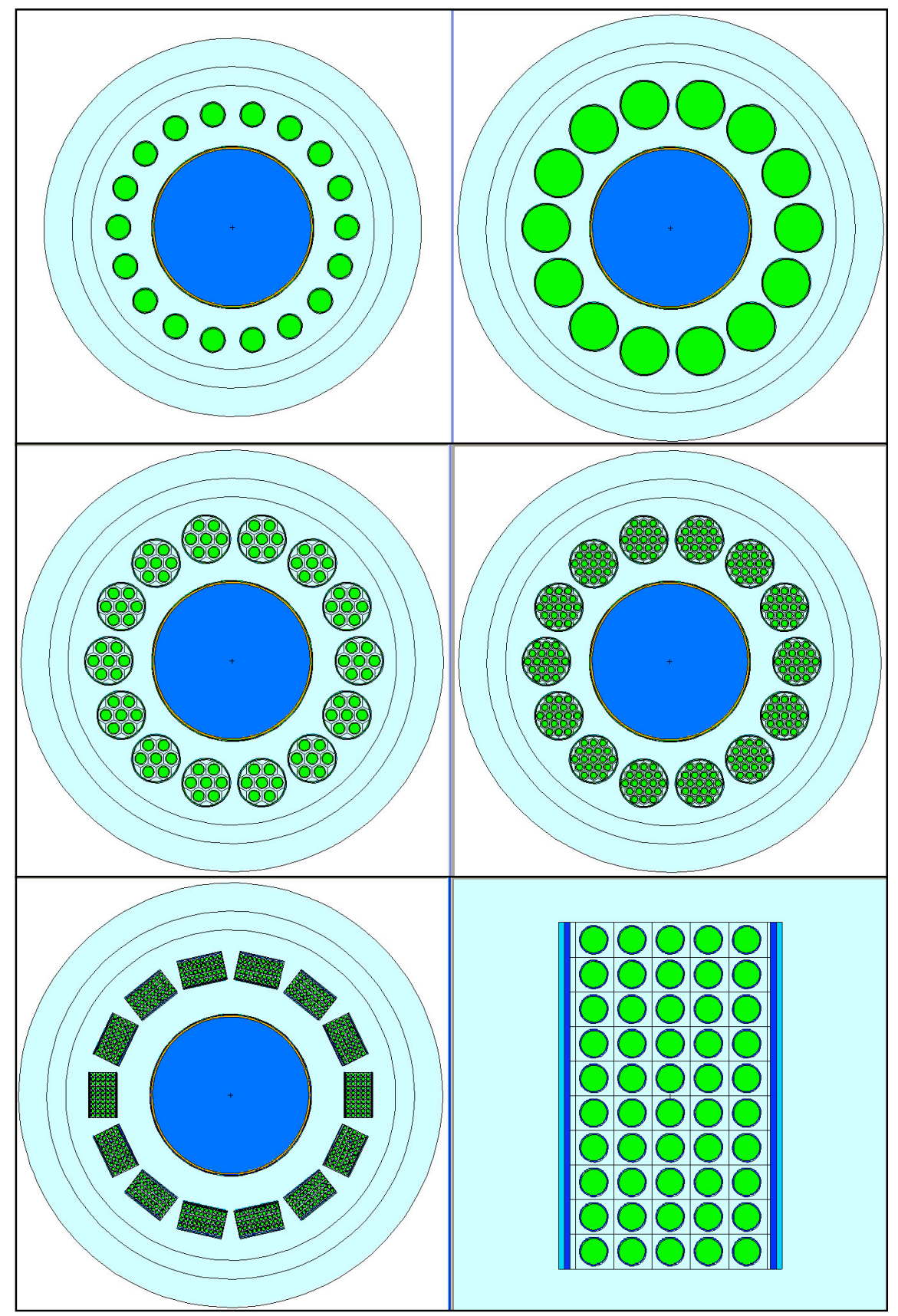

Figure 5.1. ANCC models for various tube sizes 


\section{References}

Ely JH, ER Siciliano, MT Swinhoe. 2011. Alternatives to Helium-3 for Neutron Multiplicity Detectors. PNNL-SA-77627. Proceedings of the $52^{\text {nd }}$ INMM Meeting, Palm Desert, CA, 17-21 July 2011.

Ely JH, AT Lintereur, ER Siciliano. 2011b. Interim Report on the Optimization and Feasibility Studies for the Neutron Detection Without Helium-3 Project. Technical Report PNNL-20952, Pacific Northwest National Laboratory, Richland, Washington.

Henzlova D, LG Evans, HO Menlove, MT Swinhoe, V Henzl, C Rael, I Martinez, JB Marlow. 2012. Results of the Evaluation and Comparison of Alternative Neutron Detectors for Potential 3He Replacement for Nuclear Safeguards Applications. Los Alamos National Laboratory Report LA-UR-12-00837.

Kouzes RT, JH Ely, AT Lintereur, ER Siciliano. 2012. "Introduction to Neutron Coincidence Counter Design Based on Boron-10.” Technical Report PNNL-21090, Pacific Northwest National Laboratory, Richland, Washington.

Lintereur AT, RT Kouzes, JH Ely, LE Erikson, and ER Siciliano. 2010. Boron Lined Neutron Detector Measurements. Technical Report PNNL-18938, Pacific Northwest National Laboratory, Richland, WA.

[MCNPX 2011] Pelowitz DB (ed.). 2011 “MCNPX User's Manual”, Version 2.7.0. Los Alamos National Laboratory Report LA-CP-11-00438.

Siciliano ER, JH Ely, RT Kouzes, ML Woodring. 2010. Simulating Boron-Based Detectors with MCNPX. Technical Report PNNL-SA-71579, Pacific Northwest National Laboratory, Richland, Washington. 


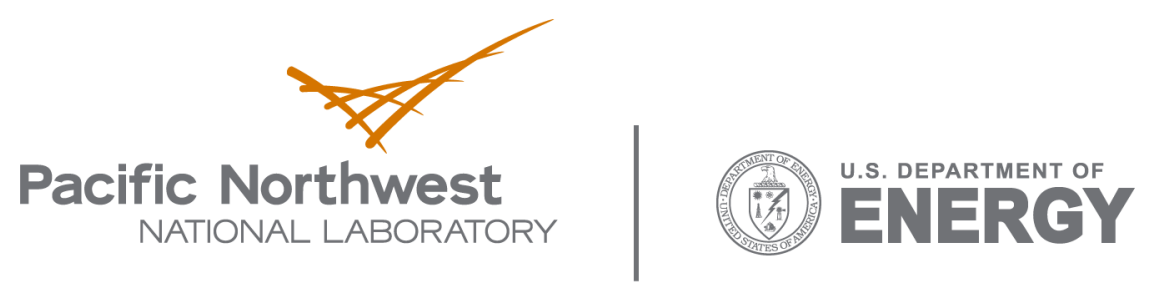

902 Battelle Boulevard

P.O. Box 999

Richland, WA 99352

1-888-375-PNNL (7665)

www.pnl.gov 